Original Article

\title{
DEMOGRAPHICS AND FACTOR ASSOCIATED WITH FOOD SUPPLEMENTS USE AMONG YOGYAKARTA POPULATION
}

\author{
RUSYDA DYAH UTARI ADITYA ${ }^{1}$, CHAIRUN WIEDYANINGSIH ${ }^{2}$, SUSI ARI KRISTINA²* \\ ${ }^{1}$ Undergraduate Student, Faculty of Pharmacy, Universitas Gadjah Mada, Yogyakarta, Indonesia, ${ }^{2}$ Department of Pharmaceutics, Faculty of \\ Pharmacy, Universitas Gadjah Mada, Yogyakarta, Indonesia \\ Email: susiari_k@ugm.ac.id \\ Received: 01 Aug 2017 Revised and Accepted: 16 Oct 2017
}

\section{ABSTRACT}

Objective: The aim of this study was to explore the prevalence of food supplement use and the association between foods supplement use and sociodemographic factors among Yogyakarta population.

Methods: A cross-sectional online questionnaire was developed and validated. A number of 933 participants completed the survey during September-December 2016. A convenience sampling technique was used. The sociodemographic characteristics and use of dietary supplements were collected. Frequency distributions were used to explore the use of food supplement. The relationship between demographic factors and dietary supplement use was conducted using pearson correlation analysis.

Results: Food supplement daily use was reported by $63 \%$ of participants. A mean number of the supplement was 2.3 (SD 2.1 ). The advertisement was commonly the source of information about food supplement. Age, sex, monthly income, excercise, and smoking status were associated with food supplement use.

Conclusion: Use of food supplements in this population was relatively high reflects that of other countries. Participants were using unreliable source of information of the benefits and risks associated with supplement consumption. Health professionals should account for dietary supplements when assessing medication. Regulating bodies and public health officers need to be aware to ensure safe practices.

Keywords: Food supplement, Vitamin, Use, Yogyakarta

(C) 2017 The Authors. Published by Innovare Academic Sciences Pvt Ltd. This is an open access article under the CC BY license (http://creativecommons.org/licenses/by/4.0/) DOI: http://dx.doi.org/10.22159/ijpps.2017v9i12.21737

\section{INTRODUCTION}

Food supplements are defined as any product intended to supplement the diet that contains one or more of the a vitamin, a mineral, an herb or other botanical, an amino acid, to supplement the diet by increasing the total dietary intake [1].

Numerous surveys have reported on health-related characteristics of supplement use prevalence, finding that supplement use is associated with a variety of habits or characteristics considered to be components of a healthy lifestyle, including trying to make better food choices. Several studies have examined lifestyle and demographic associations with dietary supplement use, finding greater use among women, older adults, and those whose levels of education or socioeconomic status are higher $[2,3]$.

Although the use of food supplements is increasing in popularity, patterns of use for these supplements are not well known, and what is available is not always consistent, clear, or easily accessible. Many studies revealed that the taking of nutritional preparations has not consistently indicated advantages other than a placebo effect or one resulting from the treatment of concurrent nutritional deficiencies [4, 5]. Consequently, according to The United States Commission on Dietary Supplement Labels, it is important for health professionals to become more attention about the use and types of supplements in order to help consumers make appropriate choices [6].

To our knowledge, no data is available either concerning use in Indonesian or Yogyakarta population. We consider Yogyakarta population' supplement consumption to fit into the prevalence patterns for developing countries. For this reason, the objective of this survey was to quantify the prevalence of food supplement usage among Yogyakarta community members; to identify supplements consumed and rationale for usage; to identify sources of supplement information, and to relate usage to selected demographic characteristics.

\section{MATERIALS AND METHODS}

A cross-sectional online questionnaire was conducted among Yogyakarta population. In all, 933 participants were involved during the period of July-September 2016.

\section{Questionnaire}

The online questionnaire was developed using Google Forms $₫$ after a review of the current literature and visits to local pharmacies, supermarkets, and health food stores to identify commonly available dietary supplements. A 26-item questionnaire was developed using a combination of multiple-choice questions and Likert scale questions. A tailored layout allowed participants to move through the questionnaire only answering relevant questions.

\section{Data collection}

Researcher contact details of respondents via social media (Facebook, Twitter, Whatsapp, Line, Instagram and a link to the questionnaire was sent to respondents in July 2016. A summary of the questionnaire, ethics approval, and inferred consent was included on the first page of the questionnaire. The questionnaire was comprised of four sections. Section 1 included information on sociodemographic and personal characteristics, including age, sex, gross monthly expenses, BMI, smoking status, and physical activity. Section 2 focused on the use of food supplements. Participants were asked if they had taken any vitamin/mineral supplements in the previous 6 mo. This was identified as an appropriate time frame to capture both daily dietary supplement use and non-daily dietary supplement use, which may be infrequent or seasonal.

The questionnaire was pretested among 30 pharmacy students. Recommendations for changes to question-wording for the purposes of maximizing interpretation and understanding of questions were completed before data collection. The final survey was anticipated to take 10 min to complete and was only available in Bahasa Indonesia. 
The study was conducted according to the guidelines in the Declaration of Helsinki and approved by the Gadjah Mada University Human Research Ethics Committee.

\section{Data analysis}

Univariate analysis consisted of the frequency of distribution of all sociodemographic and personal characteristic variables. The proportions for the categorical variables were calculated. Additionally, mean and SD were calculated for open numerical questions and calculated numerical questions. Descriptive statistics were used to investigate the frequency of dietary supplement use.
Responders were categorized as either regular users or occasionally use (non-daily use). Pearson correlation test was conducted to identify differences in frequency of consumption for age, sex, and income. Frequency distributions were calculated for each reason for use of the food supplements investigated.

The statistical analysis was performed using SPSS statistical software (SPSS for Windows, version 20.1, SPSS Inc, Chicago, IL, USA).

\section{RESULTS AND DISCUSSION}

An estimated response rate was 30.9\%, where 933 participants completed the full questionnaire.

Table 1: Characteristics of study population

\begin{tabular}{|c|c|c|}
\hline \multirow[t]{2}{*}{ Characteristics } & \multirow{2}{*}{$\begin{array}{l}\text { Daily users } \\
\mathrm{n}=592(\%)\end{array}$} & \multirow{2}{*}{$\begin{array}{l}\text { Occasionally users } \\
\mathrm{n}=341(\%)\end{array}$} \\
\hline & & \\
\hline \multicolumn{3}{|l|}{ Gender } \\
\hline Male & $130(21.96)$ & $97(28.45)$ \\
\hline Female & $462(78.04$ & $244(71.55)$ \\
\hline \multicolumn{3}{|l|}{ Age group (y) } \\
\hline$<21$ & $187(31.59)$ & $133(39.00)$ \\
\hline $21-30$ & $365(61.66)$ & $159(46.63)$ \\
\hline $31-40$ & $18(3.04)$ & $20(5.87)$ \\
\hline $41-50$ & $13(2.20)$ & $22(6.45)$ \\
\hline$>50$ & $9(1.52)$ & $7(2.05)$ \\
\hline \multicolumn{3}{|c|}{ Monthly expenses (thousand IDR) } \\
\hline$<500$ & $34(5.74)$ & $25(7.33)$ \\
\hline $500-1,499$ & $160(27.03)$ & $100(29.33)$ \\
\hline $1,500-2,999$ & $158(26.69)$ & $89(26.10)$ \\
\hline $3,000-5,000$ & $125(21.11)$ & $83(24.34)$ \\
\hline$>5,000$ & $115(19.43)$ & $44(12.90)$ \\
\hline \multicolumn{3}{|l|}{ Education level } \\
\hline Less than Junior high school & $7(1.18)$ & $8(2.35)$ \\
\hline Junior high school & $31(5.24)$ & $19(5.57)$ \\
\hline Bachelor degree & $346(58.45)$ & $199(58.36)$ \\
\hline Master degree & $182(30.74)$ & $94(27.57)$ \\
\hline unknown & $26(4.39)$ & $21(6.16)$ \\
\hline \multicolumn{3}{|l|}{ BMI (kg/m2) } \\
\hline$<24.9$ & 75 (12.67) & $49(14.37)$ \\
\hline normal & $428(72.30)$ & $251(73.61)$ \\
\hline $25-29.9$ & $80(13.51)$ & $30(8.80)$ \\
\hline$>30$ & $9(1.52)$ & $11(3.23)$ \\
\hline \multicolumn{3}{|l|}{ Smoking status } \\
\hline Non-smoker & $524(88.51)$ & $293(85.92)$ \\
\hline Former smoker & $13(2.20)$ & $17(4.99)$ \\
\hline Passive smoker & $34(5.74)$ & $21(6.16)$ \\
\hline Current smoker & $21(3.55)$ & $10(2.93)$ \\
\hline \multicolumn{3}{|c|}{ Amount of exercise (min/week) } \\
\hline$>60$ & $19(3.21)$ & $13(3.81)$ \\
\hline $30-60$ & $139(23.48)$ & $78(22.87)$ \\
\hline $0-30$ & $434(73.31)$ & $250(73.31)$ \\
\hline \multicolumn{3}{|l|}{ Perceived health } \\
\hline Healthy & $385(65.03)$ & $255(74.78)$ \\
\hline With minor illness & $168(28.38)$ & $72(21.11)$ \\
\hline With chronic disease (s) & $6(1.01)$ & $6(1.76)$ \\
\hline With severe disease (s) & $3(0.51)$ & $2(0.59)$ \\
\hline Pregnant/breastfeed & $20(3.38)$ & $3(0.88)$ \\
\hline Others & $10(1.69)$ & $3(0.88)$ \\
\hline
\end{tabular}

Table 2: Characteristics of supplement used

\begin{tabular}{|c|c|c|}
\hline \multirow[t]{2}{*}{ Characteristics } & \multicolumn{2}{|c|}{ Users (592) } \\
\hline & $\mathbf{n}$ & $\%$ \\
\hline \multicolumn{3}{|c|}{ Primary source of information } \\
\hline Health professionals & 211 & 35.64 \\
\hline Advertisement & 407 & 68.75 \\
\hline Family/peers & 303 & 51.18 \\
\hline others & 11 & 1.86 \\
\hline \multicolumn{3}{|c|}{ Supplement purchased from } \\
\hline pharmacy & 446 & 75.34 \\
\hline supermarket & 306 & 51.69 \\
\hline Online shop & 16 & 2.70 \\
\hline others & 32 & 5.41 \\
\hline
\end{tabular}


Table 1 outlines the sociodemographic and personal characteristic variables of the participants. The majority of participants were aged $<30$ y old, female, with a normal BMI, monthly expenses about 200 USD, high education level, non-smoker, low physical activity, and reported healthy status.
Overall, 592 (63.45\%) of the 933 participants reported having used at least one food supplement in daily use in the previous 6 mo (table 2). The most popular vitamin/mineral supplement reported was a vitamin and multivitamin/mineral with a prevalence of $82 \%$ and $40 \%$ of the total population respectively (table 3 ).

Table 3: Types of supplement consumed

\begin{tabular}{|c|c|c|}
\hline \multirow[t]{2}{*}{ Types of supplement consumed } & \multicolumn{2}{|c|}{ Daily users } \\
\hline & $n=592$ & $\%$ \\
\hline Vitamin & 489 & 82.60 \\
\hline Multivitamin & 241 & 40.71 \\
\hline Fish oil & 88 & 14.86 \\
\hline Herbal product & 217 & 36.66 \\
\hline Supplement for lose weight & 60 & 10.14 \\
\hline Supplement for anaemia & 177 & 29.90 \\
\hline High protein milk & 28 & 4.73 \\
\hline Calcium & 96 & 16.22 \\
\hline Supplement for pregnancy & 19 & 3.21 \\
\hline Others supplement & 90 & 15.20 \\
\hline
\end{tabular}

The mean number of vitamin/mineral supplements used by any participant was 2.3 (SD 2.1) with a range of 1 to 8 supplements used over the previous 6 mo (table 4).

Table 5 shows the odds ratios for demographic and lifestyle factors that were associated with the use of any food supplement.
Younger age, female, high-income people, and not engaging in regular physical activity were positively associated with food supplement use. Use of any type of food supplements was 2.06 times in age $<30 \mathrm{y}$ old, 2.27 times in women, 2.21 times among high-income people, and 3.2 times among respondent with a low level of exercise.

Table 4: Number of supplement used

\begin{tabular}{lll}
\hline Number of combination in supplement used & n & \% \\
\hline Single type & 144 & 24.32 \\
Combination of 2 & 192 & 32.43 \\
Combination of 3 & 130 & 21.96 \\
Combination of 4 & 73 & 12.33 \\
Combination of 5 & 34 & 5.74 \\
Combination of 6 & 10 & 1.69 \\
Combination of 7 & 7 & 1.18 \\
Combination of 8 & 2 & 0.34 \\
Mean number & $2.3(2.1)$ \\
\hline
\end{tabular}

Table 5: Relationship for selected sociodemographic factors toward the use of supplement

\begin{tabular}{lll}
\hline Independent factors & Adjusted odds ratio (95\% CI) & P value \\
Age $<30$ vs $>30$ & $2.06(1.31-3.24)$ & $0.018^{*}$ \\
Sex, female vs male & $2.27(1.03-2.67)$ & $0.037^{*}$ \\
BMI, $<30$ vs $>30$ & $1.23(0.46-3.32)$ & 0.564 \\
Monthly expense, high vs low & $2.21(1.65-3.69)$ & $0.047^{*}$ \\
Exercise, Never vs frequent & $3.20(2.18-4.72)$ & $<0.001^{*}$ \\
Health status, healthy vs unhealthy & $0.79(0.65-0.98)$ & 0.786 \\
Smoking, smoker vs non smoker & $1.67(1.08-2.88)$ & $0.021^{*}$ \\
\hline
\end{tabular}

*significant at $\mathrm{p}<0.05$

To our knowledge, this is the first survey on food supplements use conducted in Yogyakarta province, Indonesia. This study used a cross-sectional online survey to investigate the prevalence of supplement used, types of supplement used among Yogyakarta population. Current estimates show more than half $(63 \%)$ of Yogyakarta population use a dietary supplement infrequent basis. Most frequently reported supplements were a vitamin, multivitamins/multiminerals, herbal product and iron supplement for anemia. These results are more closely aligned with prevalence estimated from other developed countries $[2,4,7]$. Use of dietary supplements in the previous 6 mo was considered in this study rather than the previous 24 hour, as in many literature suggested may more accurately reflect prevalence and frequency of dietary supplement use in Indonesia.

Based on our result, food supplement use by the participants was different according to sex, age, monthly expenses, exercise, and smoking status. This finding shows that the rationale for supplements use changes according to subjects' general characteristics. Sex and age produced independent associations with vitamin and mineral supplement use. Women were two times more likely than men to use an iron supplement, and participants aged $<30$ y were more likely to use vitamin and multivitamin due to high activity. The difference of vitamin and mineral use by age and sex may be influenced by the recognition that there are different nutritional requirements for different sexes and at during different life stages $[3,8,9]$. Alternatively, these differences could be due to targeted marketing of specific dietary supplements [8-11].

For example, calcium is often marketed to improve bone health in older people, and iron is commonly marketed specifically to women. Future research in this area might help to direct public health messages around healthful food choices for different subpopulations, and to ensure health practitioners consider the likelihood of their patients consuming specific dietary supplements $[4,12]$. 
This study expanded on previous literature to find that information source from advertisement are still the majority source to justify the use of specific dietary supplements $[10,13]$. This may suggest that many dietary supplement users perceive supplements to be healthy, but are uncertain as to how they influence the functioning of their body systems. For example, the most frequently reported reason for use of calcium was for bone strength. Still, many participants reported only using such dietary supplements when sick, indicating that they may believe dietary supplements can assist in the recovery from ill health. These results may indicate that marketing of dietary supplements influences the perceptions and reasons for use of particular dietary supplements. However, the marketing messages may not always be aligned with the available scientific literature [14]. The consumer perceptions of these claims and their perceived validity are unclear. We are aware of the limitations of the present survey. Firstly, it was performed in a single setting, and therefore the sample may not be representative of all Indonesian population. Another limitation on the data was the use of the self-reporting system employed in this survey. This may have given rise to bias.

\section{CONCLUSION}

The findings of the present study show a high prevalence of food supplement use, similar to those reported in other developed countries. Various demographic characteristics include age, sex, economic status, exercise, and smoking status were shown to have an independent association with vitamin/mineral supplement use. This suggests that dietary supplements contribute to the overall dietary intake of individuals within this population. Furthermore, the broad health-related information on the benefits and risks associated with the use of dietary supplements are come from advertisement rather than from health professionals. Further research, monitoring the use of food supplements within the community should be of interest because these substances may affect health or interact with other medications. Pharmacists along with other health professionals need to consider evaluating food supplement use when assessing overall nutrient and medication use by patients. These results also warrant consideration by regulating bodies, public health officers, and educational organizations to ensure and promote safe practices.

\section{ACKNOWLEDGEMENT}

We thank all participants who participated in this survey, and the pharmacy students Ria Ramadhani, Arif Rahman, and Theresia Ratna, who helped in the collection of data.

\section{AUTHORS' CONTRIBUTION}

Data collection process was performed by Rusyda Dyah Utari Aditya, while Chairun Wiedyaningsih conducting a review on questionnaire and data analysis.
Susi Ari Kristina contributed on the design of the questionnaire, supervising data analysis process and writing manuscript.

\section{CONFLICT OF INTERESTS}

The author(s) declare that they have no competing interests

\section{REFERENCES}

1. European Food Safety Authority. Food Supplement. Vienna: EFSA; 2017. Available from: https://www.efsa.europa.eu/ en/topics/topic/food-supplements. [Last accessed on 23 Jun 2017].

2. Greger JL. Dietary supplement use: consumer characteristics and interests. J Nutr 2001;131:1339S-43S.

3. Bailey RL, Gahche JJ, Miller PE, Thomas PR, Dwyer JT. Why US adults use dietary supplements. JAMA Int Med 2013;173:355-61.

4. Harrison R, Holt D, Pattison D, Elton P. Are those in need taking dietary supplements? A survey of 21923 adults. Br J Nutr 2004;91:617-24.

5. Lyle BJ, Mares-Perlman JA, Klein BE, Klein R, Greger JL. Supplement users differ from nonusers in demographic, lifestyle, dietary and health characteristics. J Nutr 1998; 128:2355-62.

6. The United States Commission on Dietary Supplement Labels. Commission on Dietary Supplement Labels. New York: US Commission on Dietary Supplement Labels; 1997.

7. Kirk SFL, Cade JE, Barrett JH, Conner M. Diet and lifestyle characteristics associated with dietary supplement use in women. Public Health Nutr 1999;2:69-73.

8. Nichter M, Thompson JJ. For my wellness, not just my illness: North Americans' use of dietary supplements. Culture Med Psychiatry 2006;30:175-222.

9. Kwan D, Beyene J, Shah PS. Adverse consequences of internet purchase of pharmacologic agents or dietary supplements. J Pharm Tech 2009;25:355-60.

10. Story M, French S. Food advertising and marketing directed at children and adolescents in the US M. Int J Behav Nutr Phys Act 2004;1:3.

11. Suvarna YRR. Garlic: Nature's panacea. Asian J Pharm Clin Res 2015;8:8-13.

12. Karthikeyan GDR. Benefits of clinical pharmaceutical care intervention to the quality of patient's life and control hypertension. Asian J Pharm Clin Res 2014;7:223-6.

13. DeLorme DE, Huh J, Reid LN, An S. Dietary supplement advertising in the US. Int J Advert 2012;31:547-77.

14. Hathcock JN. Vitamins and minerals: efficacy and safety. Am J Clin Nutr 1997;66:427-37. 